\title{
Qualitative and quantitative estimates of apoptosis from birth to senescence in the rat brain
}

\author{
LD White ${ }^{1}$ and S Barone $\mathrm{Jr}^{*, 1}$ \\ ${ }^{1}$ Neurotoxicology Division, Cellular and Molecular Toxicology Branch, National \\ Health and Environmental Effects Research Laboratory, US Environmental \\ Protection Agency, Research Triangle Park, North Carolina, NC 27711, USA \\ * Corresponding author: S Barone Jr, Cellular and Molecular Toxicology Branch, \\ Neurotoxicology Division, Mail Drop 74B, National Health and Environmental \\ Effects Research Laboratory (NHEERL), US Environmental Protection Agency, \\ Research Triangle Park, North Carolina, NC 27711, USA. Tel: 919-541-3916; \\ Fax: 919-541-4849; E-mail: barone.stan@epa.gov
}

Received 23.3.00; revised 20.10.00; accepted 21.11.00

Edited by RA Lockshin

\begin{abstract}
Apoptosis is crucial for proper development of the CNS, wherein a significant percentage of all central neurons produced during early ontogeny die by apoptosis. To characterize the pattern of developmental programmed cell death, we assayed rat brainstem, neocortex, hippocampus, and cerebellum from birth through senescence. Quantitatively, using an ELISA for oligonucleosomal DNA fragments, we demonstrated that PND1 brainstem, neocortex, and hippocampus have the highest levels of fragmented DNA compared to older ages. Cerebellum displayed a large peak at PND10 and a smaller peak at PND21. Low levels were observed throughout adulthood and into senescence, which was corroborated qualitatively by agarose gel and TUNEL data. These data provide a temporal and regional baseline for further studies of the effects of perturbations of cell death during neural development. Quantitative and qualitative changes in these regional profiles of apoptosis due to environmental insults during early ontogeny may alter neuron number and function later in life. Cell Death and Differentiation (2001) 8, 345-356.
\end{abstract}

Keywords: apoptosis; programmed cell death; neocortex; cerebellum; brainstem; hippocampus

Abbreviations: ABTS, with 2,2'-Azino-di[3-ethylbenz-thiazolinsulfonat(6)]; CNS, central nervous system; DAB, 3,3'-diaminobenzidine hydrochloride; ELISA, enzyme-linked immunosorbentassay; PND, postnatal day; TUNEL, terminal transferase-mediated dUTP nick end labeling

\section{Introduction}

Though apoptosis is widely accepted as an integral process of central nervous system (CNS) development, ${ }^{1}$ significant data gaps exist in the regional and temporal characterization of in vivo programmed cell death. Intense investigation of this form of cell death is underway, but the magnitude of cell death that occurs during neural development is still unknown (reviewed $i^{2}$ ). Most studies of neuronal death have used cells in culture and/or induction of synchronous apoptosis in vitro by various means such as deprivation of nerve growth factor, ${ }^{3}$ ionizing radiation, ${ }^{4}$ kainate, ${ }^{5}$ and $\mathrm{Ca}^{2+}$ ionophores. ${ }^{6}$ Studies of this kind allow the induction of programmed cell death simultaneously in a large controlled population of homogenous cells, with stimulation of common signaling events leading to apoptosis. In vivo, the study of apoptosis is especially challenging because apoptotic cells are generated asynchronously, are cleared from the surrounding tissue in a few hours, and may be visibly dying for an even briefer period. ${ }^{7}$ Bursch et al. ${ }^{8}$ estimate that only $2-3 \%$ of cells in a region may be apoptotic at a given time, although as many as $25 \%$ of a population of cells per day are lost through apoptosis. Apoptosis is widespread in both the fetal and postnatal central nervous systems, with fetal cell death occurring mainly in proliferative zones and often a second wave of apoptosis occurring in post-mitotic cells. ${ }^{9,10}$

Our objective was to comprehensively characterize, using both quantitative and qualitative methods, normal apoptosis occurring in the central nervous system from birth through senescence. A number of methodologies have been used to characterize cell death both biochemically and morphologically (reviewed $\mathrm{in}^{11}$ ). It is important to use more than one detection method, as necrosis and apoptosis, which are at two ends of a spectrum of cell death, may be indistinguishable at certain stages in that continuum. We have chosen three diverse methods to assess apoptosis in the postnatal rat brain: (1) Enzymelinked immunosorbent assays (ELISA) in which an antihistone capture antibody and an anti-DNA detection antibody are used in a 'sandwich' ELISA format to detect the DNA/histone mono- and oligonucleosomes generated by nuclease cleavage of nuclear DNA. This highly sensitive method allows quantitation of apoptosis. (2) Agarose gel electrophoresis of cytoplasmic fractions, which illustrates cleavage into oligonucleosomal fragments, or ladders, in multiples of $180-200 \mathrm{bp}$, from the initial cleavage into fragments of $50-300 \mathrm{kbp}^{12,13}$ This method, when used alone, is only suggestive of apoptosis. Gel electrophoresis is semi-quantitative in that DNA loaded into each well is normalized by the amount of tissue from which the DNA was isolated (i.e., each well is loaded with DNA isolated from an equal amount of tissue). When used in conjunction with ELISA techniques, these methods can demonstrate the overall amount of fragmented DNA and the size of DNA fragments generated. (3) TUNEL assay in which the myriad free $3^{\prime}-\mathrm{OH}$ ends generated by DNA fragmentation are enzymatically labeled using terminal transferase followed by visualization with an immunoperoxidase reaction product to stain apoptotic cells. This in situ method, while of use for quantification, is used in this study to provide valuable information about cellular localization and anatomical detail. 
False positives may be encountered with this method, as some necrotic cells can be stained. ${ }^{14,15}$ The current animal study delineating disparate patterns of apoptosis in different brain regions contributes to an understanding of the normal ontogenetic cell death that occurs during brain development. These patterns establish a baseline for further studies to examine pertubations of apoptosis in early ontogeny that may alter neuron number and serve as an antecedent to loss of function occurring later in life.

\section{Results}

Two general qualitative patterns of ontogeny were apparent from the quantitative determinations of apoptosis from cell death ELISAs (Figure 1). The first pattern defined included peaks, and could be described by high levels of fragmented DNA followed by significantly lower levels, and the second pattern included asymptotic plateaus, which were found in adult animals, where levels of fragmented DNA were low and did not change appreciably with further aging. While similarities existed in the qualitative patterns of apoptosis in brainstem, neocortex and hippocampus ELISA, the quantitative pattern, however, for each region was considered unique due to significant interaction of age and brain region in the overall ANOVA $(P<0.001)$. Step-down ANOVAs of each region revealed significant effects of age $(P<0.001)$ in all regions examined. Post hoc analysis with Tukey's multiple comparison test within each region demonstrated significant differences among ages.

Brainstem, neocortex and hippocampus had somewhat similar patterns of apoptosis postnatally, but temporal shifts were apparent which account for the significant differences between these regions. For these three regions, a high level of fragmented DNA at PND1 is followed by a reduction during the first postnatal week to a basal plateau by PND90. However, the pattern of decrement to the adult asymptotic plateau was different between neocortex and brainstem, with brainstem reaching an asymptotic plateau more gradually than neocortex. The absolute levels of fragmented DNA were high at PND1 in both regions and low in adulthood in both regions. The hippocampal formation at PND1 was at its peak, and had less than a third the amount of fragmented DNA as compared to neocortex and brainstem, and further, had levels below detectable limits of the assay in adulthood. Patterns of cerebellar apoptosis were unique compared to other
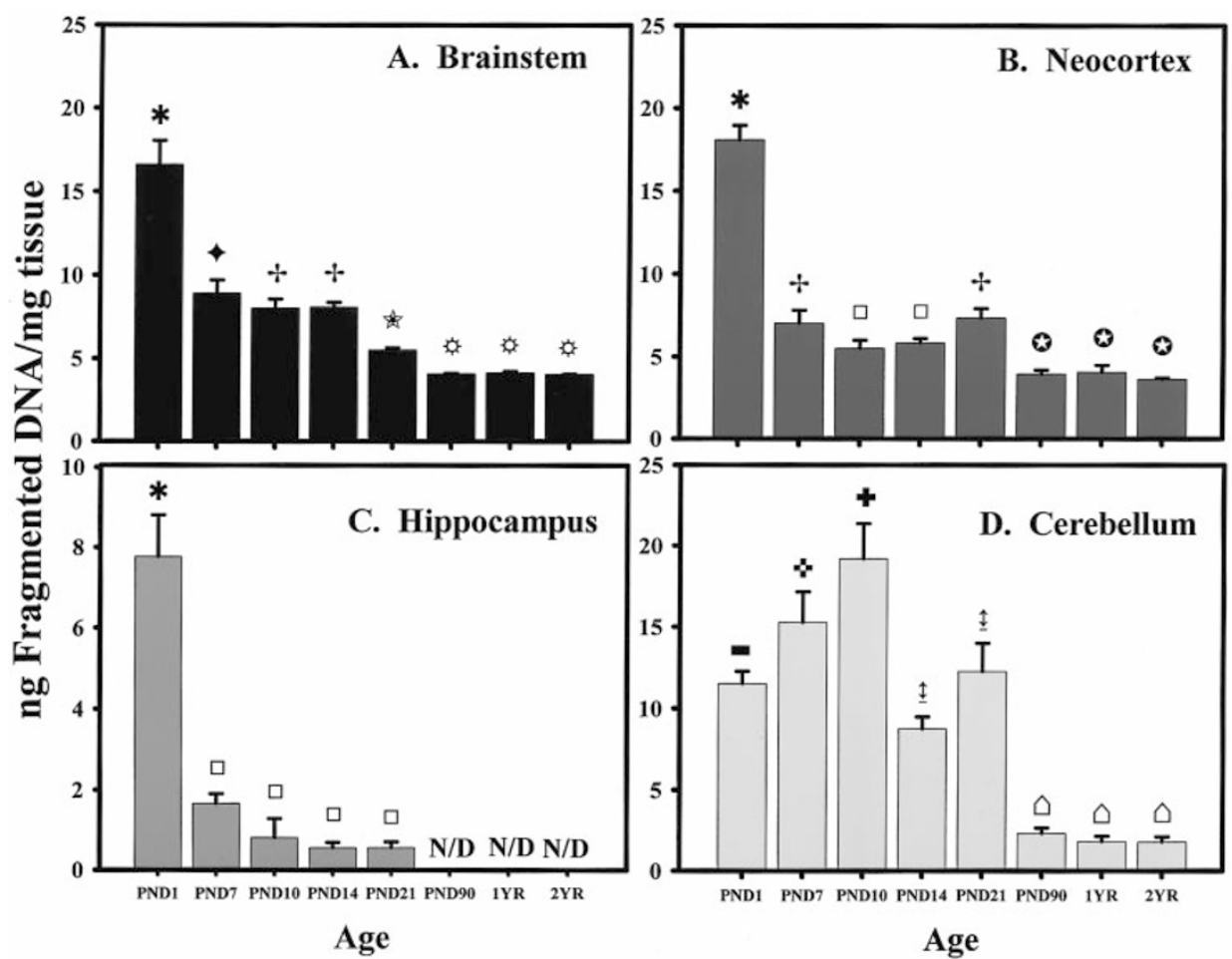

Figure 1 Developmental profile of apoptosis in brainstem (A), neocortex (B), hippocampus (C), and cerebellum (D) expressed as ng fragmented DNA/mg tissue, at ages PND 1, 7, 10,14, 21, and 90 and 1 year and 2 year. Note that with respect to age within earlier developing regions, Brainstem (A), Neocortex (B), and hippocampal formation (C) had higher levels of fragmented DNA on PND1. Cerebellum (D), a later developing region, showed the most unique regional pattern with its peak apoptosis at PND10. Note that with aging, Brainstem (A) and Neocortex (B) had higher levels of fragmented DNA compared to the cerebellum (D) and hippocampal formation. Data are expressed as mean \pm S.E. Symbols indicate significant differences:

* All other ages

- PND1, PND7 and PND21

+ PND1 and PND21 through 2YR

- PND10, PND90, 1YR and 2YR

+ PND1 and PND90 through 2YR

* PND1 and PND7

* PND1 through PND14

- PND1

* PND14, PND90, 1YR and 2YR

- PND1 and PND14 through 2YR

\$ PND90, 1YR and 2YR

- PND1 through PND21 
regions in that a peak developed at PND10 followed by a smaller increase at PND21. Cerebellum was similar to other regions in having a lower asymptotic plateau of apoptosis from adulthood through senescence.

\section{Brainstem}

ELISA data (Figure 1A) showed levels of brainstem apoptosis to be highest (and significantly different from all other ages in this region) at PND1 and to decline in step-wise fashion to adulthood. The first significant phase of the decline, from PND1 to PND7, was approximately a 50\% decrease. Apoptosis rates leveled off somewhat from PND7 through PND14, such that PND7 was significantly different from PND21 through adulthood, and PND10 and 14 were significantly different from PND90 though adulthood. Levels of fragmented DNA in the brainstem reached an asymptotic plateau at PND21 that extended through 2 years. Adult levels of apoptosis were not significantly different from each other in this region. Agarose gel electrophoresis of brainstem tissue gave results consistent to those seen by ELISA (data not shown). TUNEL-staining of PND1 brainstem (Figures 2A, 3A and $4 \mathrm{~A}$ ) was the highest compared to other ages, and showed apoptotic cells in the inferior olive (Figure $3 A$ ) and raphe nuclei with scattered distribution throughout other areas of the brainstem. A few apoptotic cells were visible and scattered throughout the brainstem at PND7 and PND10 (Figures 2B,C and 4B-D). At PND14, a few apoptotic cells in the dorsal cochlear nucleus were seen, and sparse TUNEL-staining was evident at PND21 (Figures 4F and 5A). Very little TUNEL

\section{TUNEL - Staining for Apoptosis}
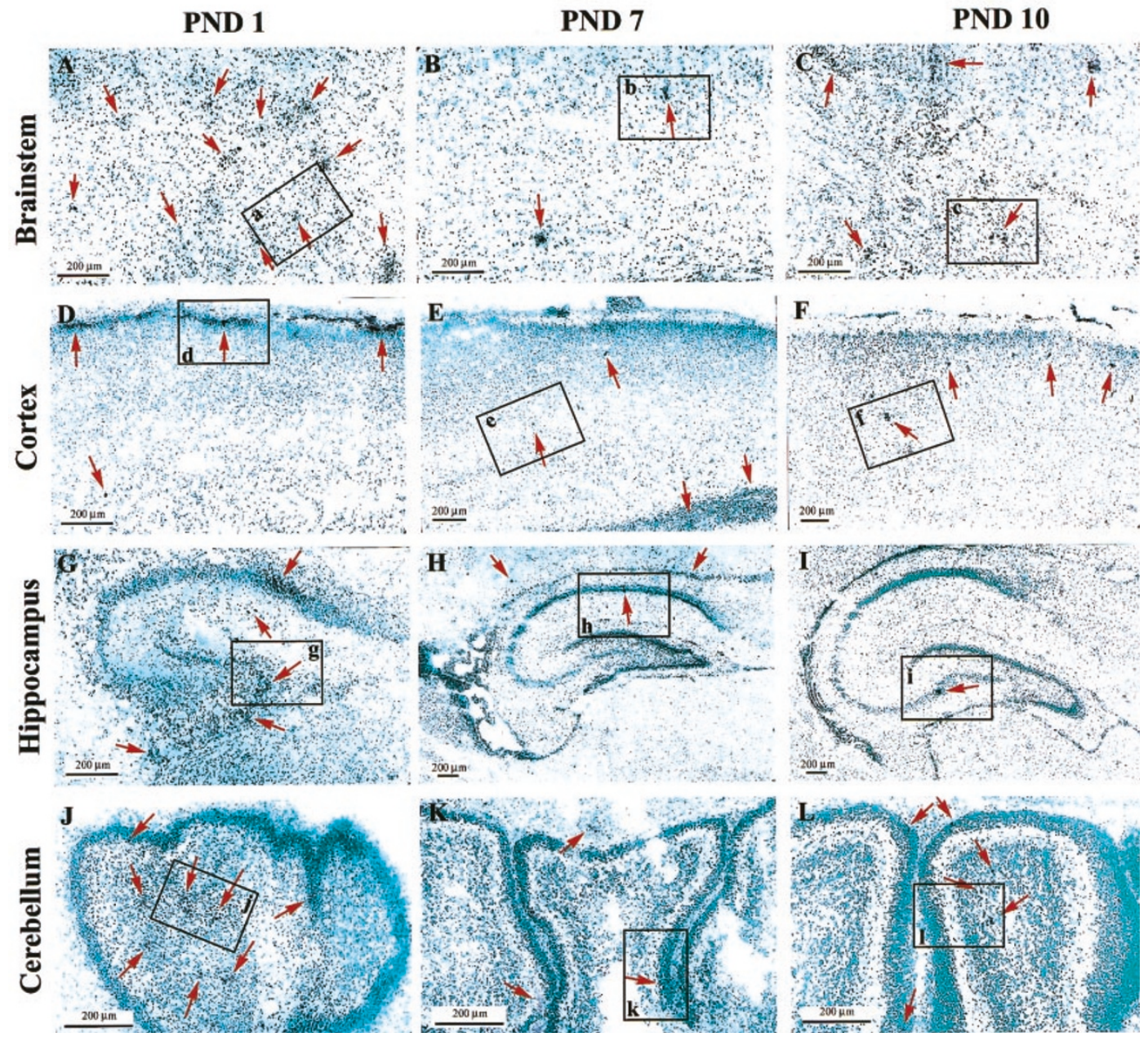

Figure 2 Photomicrographs of TUNEL-stained sagittal sections of brainstem (A,B,C), neocortex (D,E,F), hippocampus (G,H,I) and cerebellum (J,H,I) at ages PND1, 7 and 10. Note that red arrows point to black immunoperoxidase reaction product of TUNEL-staining. All sections are counter stained with methylene green to reveal cytoarchitecture. Micron bars denote relative magnification in each panel 


\section{Tunel Staining - High Magnification}
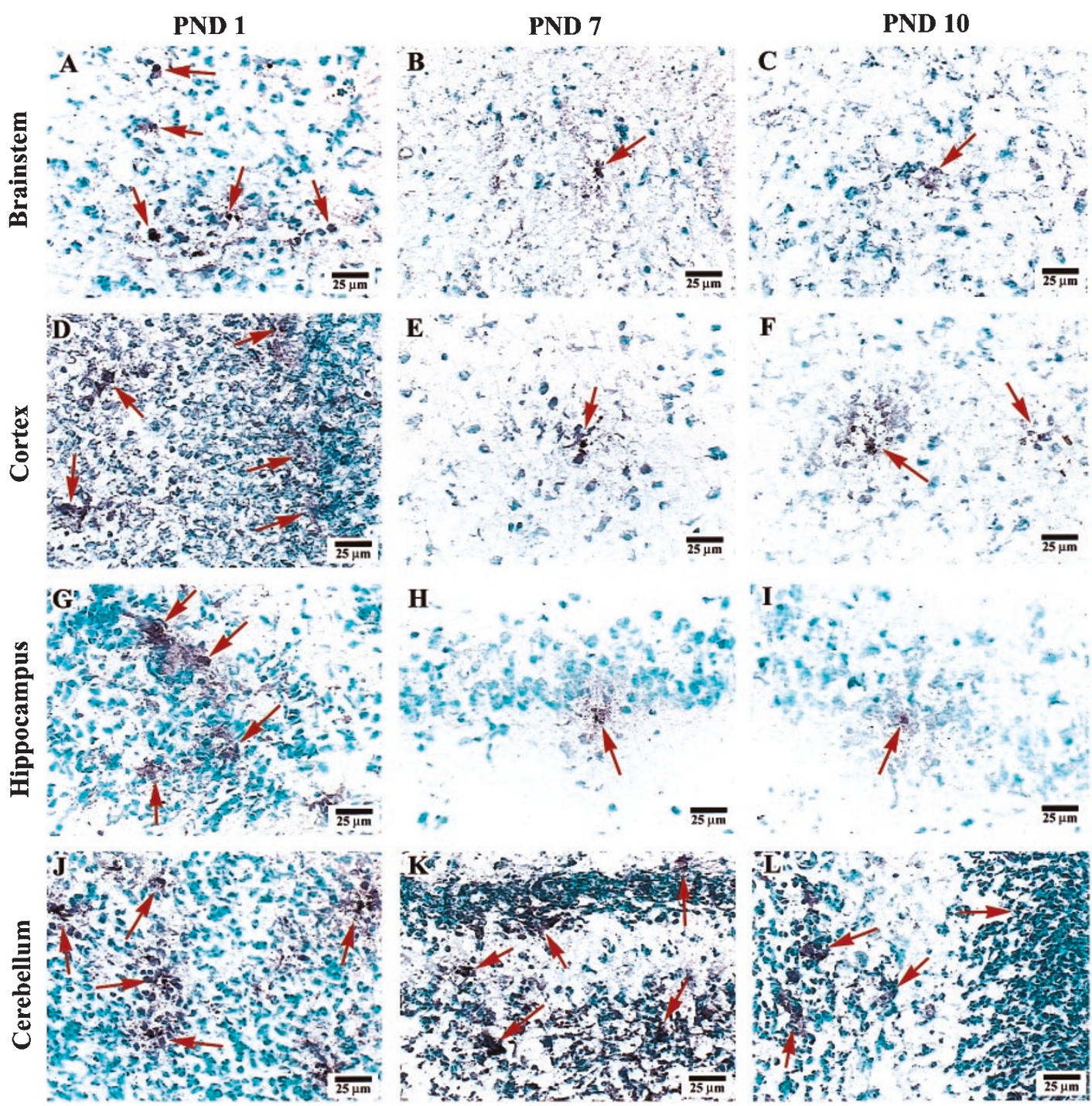

Figure 3 Higher magnification photomicrographs of TUNEL-stained sagittal sections (boxed regions in Figure 2) of brainstem $(\mathbf{A}, \mathbf{B}, \mathbf{C})$, neocortex (D,E,F), hippocampus $(\mathbf{G}, \mathrm{H}, \mathrm{I})$ and cerebellum $(\mathrm{J}, \mathrm{H}, \mathrm{I})$ at ages PND1, 7 and 10 . All sections are counter stained with methylene green to reveal cytoarchitecture. Micron bars denote relative magnification in each panel

staining was observed at later ages in brainstem (Figures $4 \mathrm{G}, \mathrm{H}$ and $5 \mathrm{~B}, \mathrm{C})$. Age- and region-dependent distribution of TUNEL staining appeared to be in agreement with both ELISA and gel data.

\section{Neocortex}

Apoptosis, as quantified by cell death ELISA (Figure 1B), displayed a relatively large peak at PND1 and dropped to very low levels by adulthood. The sharpest decline in the amount of fragmented DNA was from PND1 to PND7, approximately $60 \%$. A small increase in levels of fragmented DNA from PND14 to PND21 demonstrated a latent peak in postnatal development where differences from adult levels were observed. A lower asymptotic plateau, with low but significant levels of fragmented DNA, similar to those seen in brainstem continued into senescence. Fragmented DNA, as visualized by agarose gel electrophoresis was consistent with ELISA data and showed intense oligonucleosomal banding patterns at PND1 (data not shown). TUNEL-stained sagittal sections (Figures 2D, 3D and 4A) revealed large numbers of apoptotic cells at PND1. These cells were located mostly in the proliferative zone of the ventricular layer and the pial surface of the neocortex. Additionally, greater numbers of cells were observed in the posterior aspects of the neocortex proximal to the splenic flexure compared to anterior aspects of the cortical mantle. A sharp decline in the number of apoptotic cells was evident by PND7 (Figures 2E, 3E and 4B), with post-migratory apoptotic cells visible in layer 2 and in deeper layers. A rostralto-caudal gradient persisted with more prominent apoptotic profiles present in posterior aspects of the neocortex versus anterior aspects. By PND10 (Figures 2F, 3F and 4C,D), only 


\section{Ontogeny of TUNEL-IR}

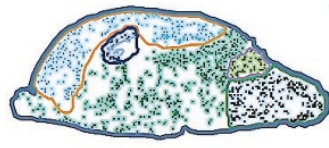

A. PND 1 Medial

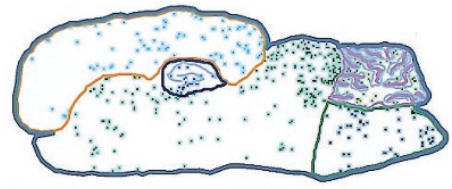

B. PND 7 Medial

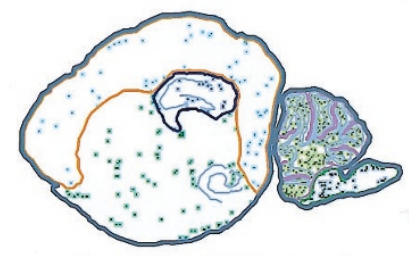

C. PND 10 Lateral

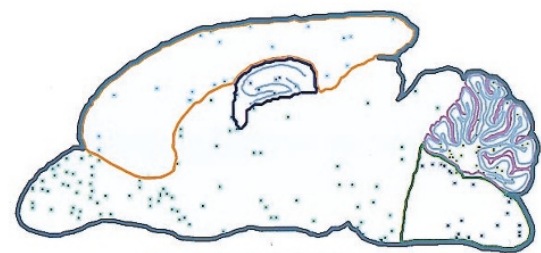

E. PND 14 Medial

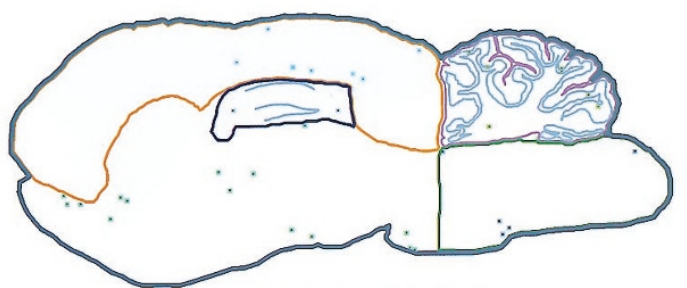

G. 1 YEAR Medial

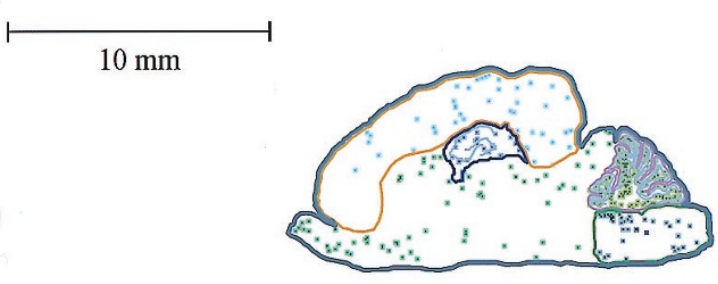

D. PND 10 Medial

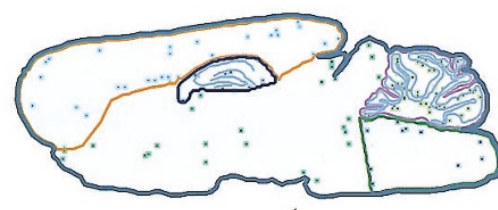

F. PND 21 Medial

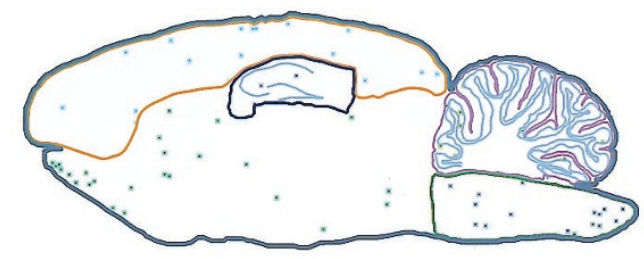

H. 2 YEAR Medial

Figure 4 Camera lucida illustration of TUNEL-stained sagittal brain sections at ages postnatal day 1 through 2 years old. Brainstem, neocortex, hippocampus, and cerebellum are drawn in green, orange, blue and pink, respectively, with the distribution of apoptotic cells in each region indicated by dots

one or two cells per field were visible and sparsely distributed from the subplate to layer II in neocortex. At ages PND14 (Figure 4E) and 21 (Figures 4F and 5D) a shift in the distribution pattern was apparent with apoptotic profiles being localized to layer I and corpus callosum, both layers lacking neuronal cell bodies. At older ages (Figures 4G,H and 5E,F) very few apoptotic cells were apparent with TUNEL staining. The distribution and the relative number of TUNEL stained cells were generally synchronous with ELISA and gel results.

\section{Hippocampus}

Hippocampal apoptosis, as quantified by ELISA (Figure 1C), displayed a generally similar pattern to that seen in neocortex. However, quantitatively, PND1 levels of fragmented DNA were only $40 \%$ of those seen in neocortex. Further, the decline in apoptosis from PND1 to PND7 was steeper in hippocampus than in neocortex and brainstem, with PND7 hippocampus having $25 \%$ of the amount of fragmented DNA as PND1 hippocampus. Beyond PND21 the amount of fragmented DNA in adult animals was below the assay's range of detection. Agarose gel electrophoresis reiterated the patterns seen with the cell death ELISA, with band intensity at PND1 in hippocampus much less than seen in neocortex at PND1 (data not shown). PND1 hippocampal levels of DNA fragmentation were approximately 10-fold higher than adult levels, in which oligonucleosomal bands were extremely faint. TUNEL-staining of PND1 hippocampus 


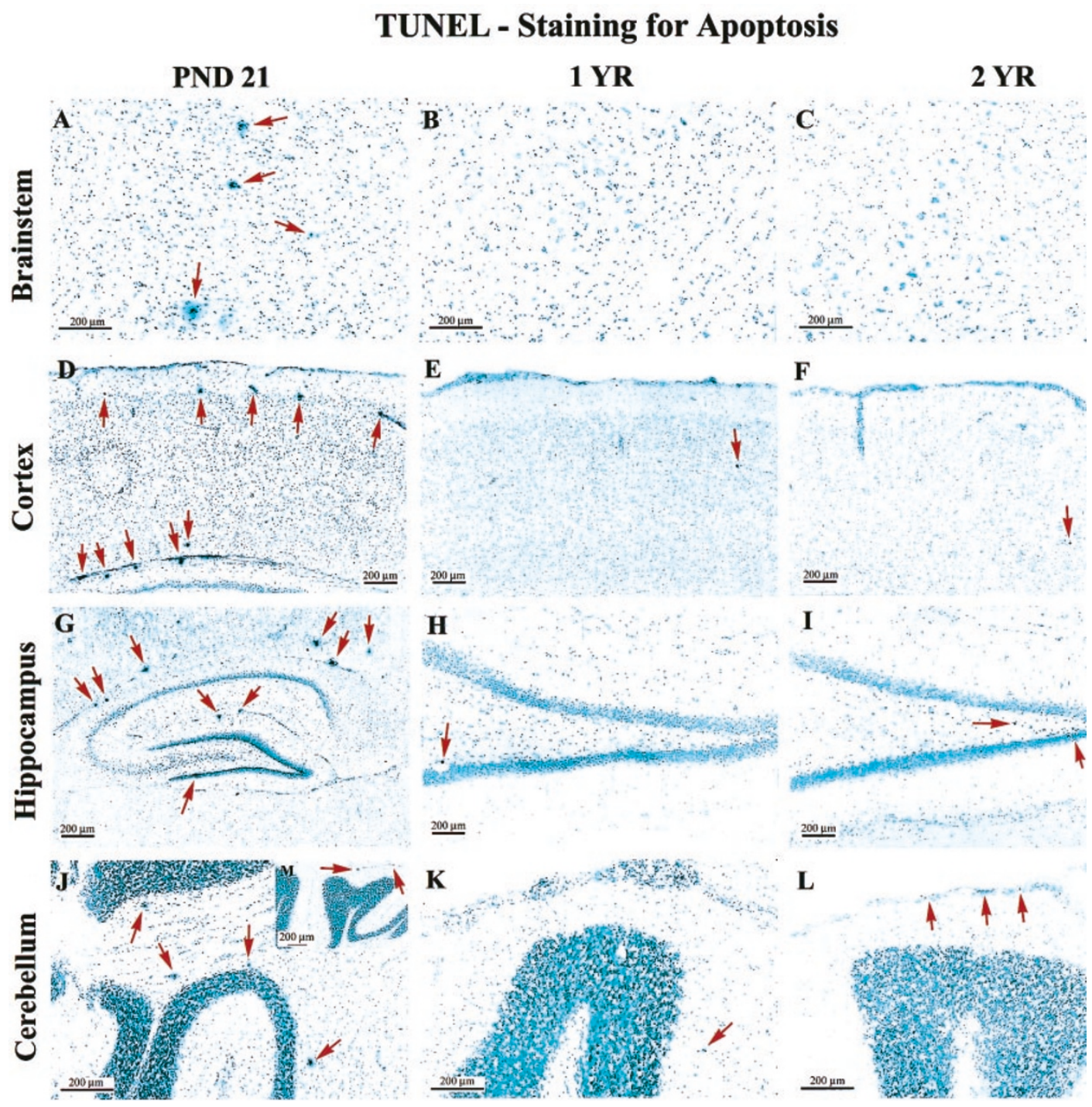

Figure 5 Photomicrograph of TUNEL-stained brainstem (A,B,C), neocortex (D,E,F), hippocampus (G,H,I) and cerebellum (J,H,I) at ages PND21, 1YR and 2YR. Note that red arrows point to black immunoperoxidase reaction product of TUNEL-staining. Note that on PND21 in neocortex (D), hippocampal formation (G) and cerebellum $(\mathbf{J}, \mathbf{M})$ that apoptotic profiles are limited to white matter areas. All sections are counter stained with methylene green to reveal cytoarchitecture. Micron bars denote relative magnification in each panel

(Figures $2 \mathrm{G}$ and $4 \mathrm{~A}$ ) demonstrated moderate numbers of cells in the more lateral regions of the hippocampal formation, most of which were adjacent to the CA1-4 pyramidal cell field and extending into the subiculum. Some apoptotic cells were present in the upper blade of the dentate gyrus at PND1. By PND7 (Figures $2 \mathrm{H}, 3 \mathrm{H}$ and 4B), labeling was much sparser than PND1 but the distribution pattern was similar. At PND10, the hippocampus (Figures 2I, 3I and $4 C, D)$ had little labeling except for a few premigratory cells in the proliferative zone of the dentate gyrus and scant labeling of cells in the subiculum and presumptive glial profiles in the white matter along the hippocampal fissure. At PND21, the only notable apoptotic profiles apparent were in the dentate gyrus and in the white matter along the alveus and the hippocampal fissure (Figures $4 \mathrm{~F}$ and $5 \mathrm{G}$ ). At the older ages, apoptotic cells were rare or nonexistent in TUNEL-stained hippocampal sections (Figures 4G,H and $5 \mathrm{H}, \mathrm{I}$ ).

\section{Cerebellum}

Of the four regions examined in detail, the temporal pattern of the cerebellum was the most unique (Figure 1D). On PND7 and 10, fragmented DNA levels were 130 and $160 \%$, respectively, of PND1 levels. A drop at PND14 was followed 


\section{PND 1}

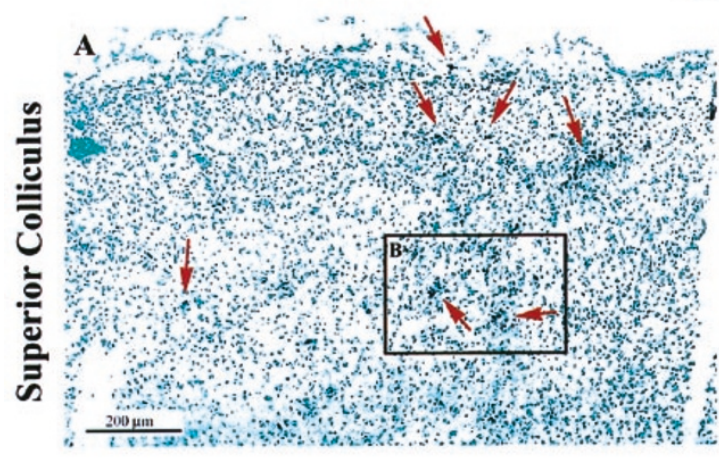

PND 1
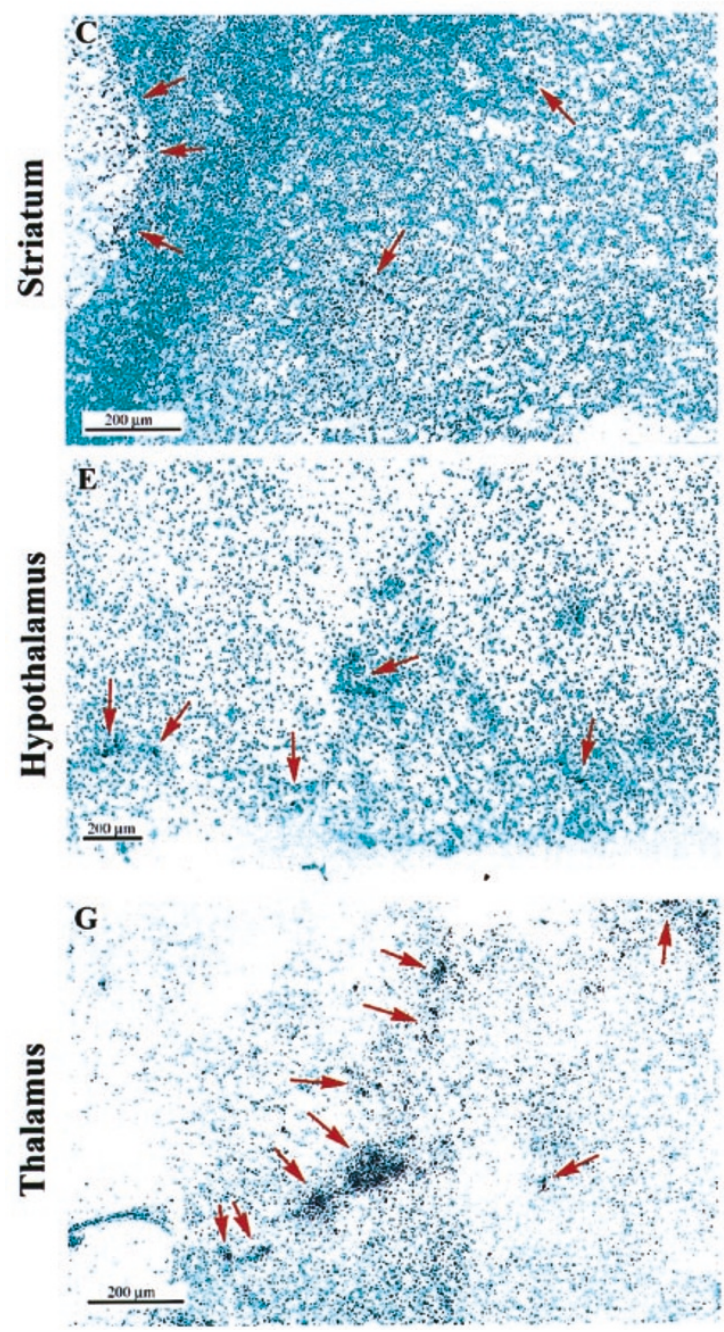

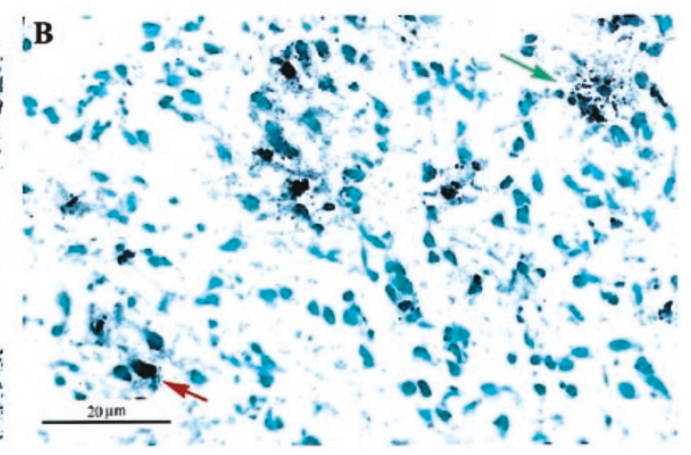

PND 7
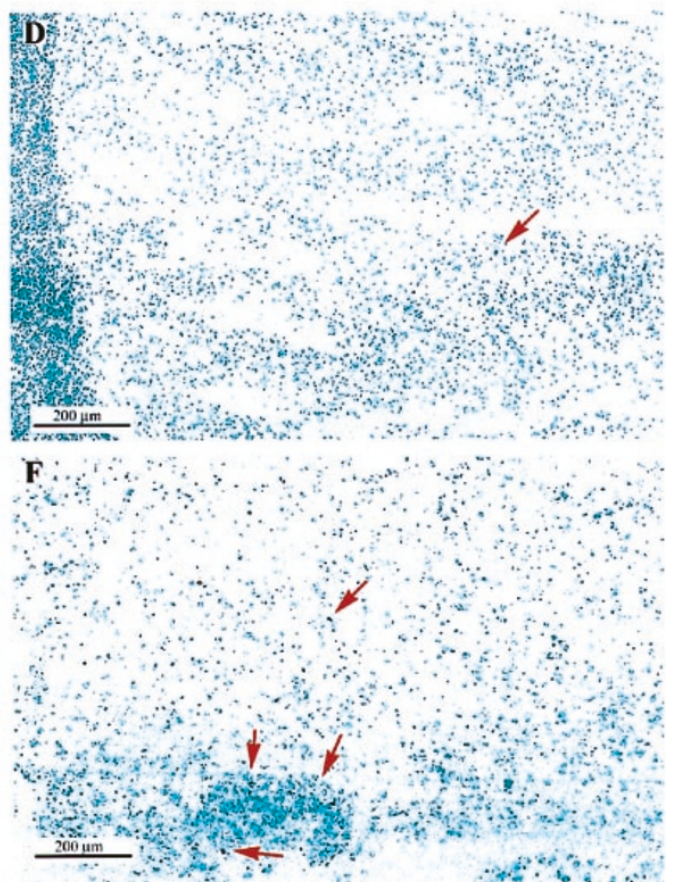

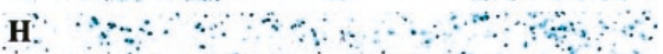

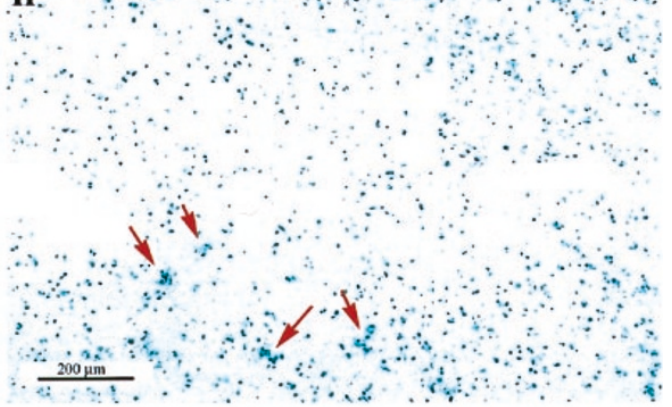

Figure 6 Photomicrograph of TUNEL-stained sagittal sections of superior colliculus at PND1 at lower (A) and higher (B) magnification. PND1 and 7 TUNELstained sagittal sections of striatum ( $\mathbf{C}$ and $\mathbf{D})$, hypothalamus ( $\mathbf{E}$ and $\mathbf{F}$ ), and thalamus ( $\mathbf{G}$ and $\mathbf{H})$. Note that red arrows point to black immunoperoxidase reaction product of TUNEL-staining. Note that the box in panel $\mathbf{A}$ of superior colliculus is shown at higher magnification in $\mathbf{B}$. Red arrow denotes typical early apoptotic profile, while green arrow (upper right hand corner) denotes sunset pattern of later apoptotic profile. All sections are counter stained with methylene green to reveal cytoarchitecture. Micron bars denote relative magnification in each panel 
by a significant increase at PND21 to just over PND1 levels. The three oldest ages had very low levels of fragmented DNA. These results were confirmed by gel electrophoresis, in which relative differences in band intensities matched ELISA data (data not shown). In situ TUNEL- staining (Figures 2J, 3J and $4 \mathrm{~A})$ revealed apoptotic cells in the external granule cell layer on PND1 in more lateral regions and significant labeling in central areas of the cerebellar rudiment. At PND7, apoptotic cells were found mostly in postmigratory cells of the internal granule cell layer, with some staining in the external granule cell layer (Figures $2 \mathrm{~K}, 3 \mathrm{~K}$ and $4 \mathrm{~B}$ ). Both pre- and postmigratory granule cells were observed at PND10 (Figures 2L, $3 \mathrm{~L}$ and $4 \mathrm{C}, \mathrm{D})$, with a greater number in post-migratory cells and cells in the deep nuclei of the cerebellum. By PND14 (Figure 4E), sparser staining of apoptotic profiles was observed in both pre- and post-migratory cells in the external and internal granule cell layer, respectively. By PND21 (Figures 4F and 5J), there was a precipitous decrease in the number of apoptotic cells found in the granule cell layer of the cerebellum, while the profiles that were observed were generally limited to the white matter of the molecular layer and the medullary layer of the cerebellum. At older ages, apoptotic profiles were observed in white matter and at the pial surface (Figures 4G,H and 5K,L). Overall, the distribution of TUNEL immunoreactive cells in the cerebellum was in general agreement with results seen with ELISA and gel experiments.

\section{Other regions}

TUNEL-staining of serial sections afforded the examination of other regions beyond the neurochemical analysis of apoptosis and deserves brief description. Relatively dense patches of apoptotic cells were observed in the superior and inferior colliculi (Figures $4 A$ and $6 A, B$ ) and the ventricular zone of the primordial striatum at PND1 (Figures 4A and 6C). In addition, patches of apoptotic profiles were observed on PND1 in the ventral hypothalamus (Figures $4 \mathrm{~A}$ and $6 \mathrm{E}$ ) and other thalamic nuclei (Figures 4A and 6G). On PND7, patches of staining were observed in the colliculi and sparsely distributed profiles were observed throughout the striatum (Figures 4B and 6D) and other nuclei of the diencephalon (Figures $4 \mathrm{~B}$ and $6 \mathrm{~F}, \mathrm{H}$ ). This staining in the striatum and colliculi was also observed at PND14 (Figure 4E), but was much sparser and virtually no staining was observed in these and other regions at later ages (Figure 5F-H).

\section{Discussion}

In mammalian neural development, the brainstem is ontogenically the oldest region of the brain. ${ }^{16}$ The development of the neocortex and hippocampal formation start later during the prenatal period, and continue developing during the first three postnatal weeks after birth in the rat. ${ }^{16}$ We have shown, postnatally, that these three regions have somewhat similar patterns of apoptosis which includes a high level at PND1, followed by a sharp decline during the first postnatal week, to very low levels during adulthood. Other laboratories that have examined naturally occurring apoptosis in the central nervous system during selected developmental windows have also found that the greatest amount of apoptotic cell death occurs during the first week of postnatal development, ${ }^{17}$ with a key exception, the late-developing cerebellum. The relative patterns of apoptosis determined from ELISA, TUNEL and agarose gel electrophoresis data were reasonably consistent in all four regions examined. Fragmented DNA, visualized in agarose gels, did not display a discrete banding pattern as often seen in gels of DNA from apoptotic cultured cells, though the fragmented DNA was the correct size for oligonucleosomal fragments. Others have observed similar 'smeared' results with DNA isolated from tissue containing apoptotic cells ${ }^{18}$ or have been unable to demonstrate 'ladders' in cultured cells that are undergoing apoptosis as demonstrated by other criteria. ${ }^{19}$ Our current agarose gel results may be explained by the small percentage of cells undergoing apoptosis at a given time in the tissue. Even at PND1 in the neocortex, the dying cells are at a series of stages of cell death, from the early $50-300 \mathrm{~kb}$ fragments, to multiples of the 180-200 base oligonucleosomes, to further degraded pieces of nucleic acids. Thus, a smear is visualized with most of the DNA migrating at the $\sim 200-800$ base size.

The process of apoptosis is intimately linked, and occurs in concert with, two other developmental processes, proliferation and migration. ${ }^{9,10}$ In very general terms, the amount of apoptosis can be considered inversely related to the maturity of a specific region of the nervous system. This study, to our knowledge, is the first large-scale temporal and regional examination, with both qualitative and quantitative descriptions, of the regional patterns of apoptosis in rat brain. This characterization will be an important contribution for further elucidation of mammalian central nervous system development and serve as a foundation in our understanding of normally occurring apoptosis.

\section{Brainstem}

Our finding of sharply diminished levels of apoptosis during the first postnatal week in brainstem is the first known description of this region's pattern of naturally occurring programmed cell death. These findings parallel previous studies of neurogenesis of this brain region ${ }^{16}$ in which cells of the brainstem develop mostly prenatally with little proliferation occurring postnatally. Little research has been done, to date, to ascertain the pattern of developmental apoptosis in the brainstem except for a recent study of human fetuses. ${ }^{20}$ The periaqueductal gray region had high apoptotic indices, as determined by TUNEL-staining, at four ages (gestational weeks 14, 18, 27, and 32). They further found an inverse correlation between apoptosis and the apoptosis-modulating oncogene protein $\mathrm{Bcl}-2$ in this and other regions. ${ }^{20}$

\section{Neocortex}

We have described the temporal pattern of apoptosis in neocortex of the rat, in which most cell death occurs in the first week of postnatal development, with the highest level at PND1 and a less dramatic latent peak at PND21. Others have also shown peaks of developmental programmed cell death in rat cerebral cortex and thalamus occurring during the first postnatal week. ${ }^{17}$ Apoptosis has been thought to reduce the variability (in weight and in DNA and protein content) of 
cerebral hemispheres in the rat during early postnatal development. ${ }^{21} \mathrm{~A}$ study of embryonic and postnatal mice showed apoptosis of proliferative neuroblasts in the cerebral cortex and discussed a possible correlation between the start of differentiation and the beginning of apoptosis. ${ }^{10}$ It is notable that this latent peak in apoptosis is coincident with the distribution of apoptotic profiles in white matter regions and in cells that either presumably failed to migrate from the subplate or are radial glia.

\section{Hippocampus}

Hippocampal apoptosis occurring during early postnatal development was also highest on PND1. In a study of the developing rat dentate gyrus, cell death was shown to occur during the early postnatal period and was suggested to be regulated by adrenal steroids, via excitatory amino acids. ${ }^{22}$ Presumptive hippocampal apoptotic neurons, identified by an antibody to caspase-3 cleavage site, were found at PND1 and 4 in the subventricular zone of CA3 and in stratum oriens ${ }^{23}$ and by PND14, few cells were immunoreactive for caspase-3. The early temporal profile described here for hippocampal apoptosis is similar to previous studies. ${ }^{22,23}$ This study indicates that basal levels of apoptosis during adulthood and senescence are lower than other cortical regions (neocortex and cerebellum) as well as brainstem.

\section{Cerebellum}

Cerebellum, a region which develops chiefly postnatally in the rat, ${ }^{16}$ has a peak in apoptosis at PND10, followed by a smaller peak at PND21, and then resolving to lower levels in adulthood. Tanaka and Marunouchi ${ }^{24}$ examined apoptosis in the rat cerebellum on days PND3, 6, 9,12, and 15 and found a peak at PND9, which is in general agreement with our findings. However, they found dead cells mainly in the external granule cell layer, a proliferative zone, whereas we saw both pre- and postmigratory cells undergoing apoptosis at this age. In addition, organotypic slice cultures have further demonstrated that proliferative cerebellar neurons undergo apoptosis. ${ }^{25}$ In the current study, the first peak of apoptosis ascertained from the ELISA data corresponds with the appearance of apoptotic cells which are presumably neurons because of their distribution in the external and internal granule cell layer; while the second smaller peak, observed in the ELISA data at PND21, corresponds with apoptotic cells in the white matter, which are likely glia. In the developing rat cerebellum, it has been suggested that a large percentage of apoptotic cells are glia. ${ }^{26}$ Previously, Taglialatela et al. ${ }^{27}$ reported that levels of apoptosis did not change from 6 to 24 months in cerebellum of Fisher rats. Our results are consistent with this previous study, demonstrating a protracted low level of apoptosis from PND90 through 24 months.

\section{Other regions}

Though not quantified, we observed the most dense TUNELstaining of apoptotic cells in the PND1 rat brain colliculi (in both inferior and superior) and thalamus. Similar to the four regions quantified, staining levels in other regions of the brain declined with age. TUNEL analysis of the postnatal rat striatum demonstrated the greatest amount of apoptosis on PND1, followed by a decrease at PND7, and after the second postnatal week, no TUNEL-positive cells were observed, consistent with a previous report. ${ }^{28}$ In the sexually dimorphic hypothalamic nucleus of gerbils, stereological determinations showed males to have the greatest number of apoptotic cells at PND0-3, whereas females had the greatest number of apoptotic profiles at PND3-6. By PND15, few apoptotic cells were seen in this area of the hypothalamus. ${ }^{29}$ Current results in rats demonstrated large numbers of apoptotic cells at PND1, fewer at PND7 and low levels at older ages. Thus, many, but not all, other brain regions display a pattern of apoptosis much like the brainstem, neocortex and hippocampus, where, in general, most programmed cell death occurs early in the first postnatal week in the rat. This study demonstrates that early apoptosis during development of cortical regions occurs in premigratory and postmigratory areas. Later waves of apoptosis are more limited and appear to be present in postmigratory cells of probable glial phenotype.

Messenger RNAs and proteins involved in control of developmental apoptosis are currently being characterized (reviewed $\mathrm{in}^{30-32}$ ). In the mouse brain, activated caspase- 3 was associated with apoptosis of neuroepithelial cells in early development, but not with cell death of postmitotic neurons during later development. ${ }^{33}$ Death of cerebellar granule cells during the second week of postnatal life has been shown to be both p53-dependent and p53-independent, depending on the stimulus. ${ }^{34}$ Expression of mRNA for the apoptosis-inhibiting protein $\mathrm{Bcl}-\mathrm{x}$ has been shown to be low at birth, followed by an increase to higher levels in the adult brain. ${ }^{35}$ These studies are in accord with our findings of high rates of apoptosis during early postnatal development, followed by a sharp decline culminating in very low levels in adulthood and senescence.

Characterization of normal patterns of developmental apoptosis are essential for discernment of the consequences of environmentally-stimulated increases or decreases in rates or in temporal occurrence of apoptosis. The purpose of this study was to establish a baseline prior to further studies in which this pattern of normal developmental apoptosis is perturbed by external stimuli resulting in aberrant development of the nervous system. This is predicated on the increasingly apparent linkage of apoptosis with a number of epigenetic and genetic conditions which include toxic exposures and neurodegenerative diseases. ${ }^{36}$ The investigation of neurotoxicological perturbations of apoptosis during neuronal development is relatively uncharted ground; however, it deserves attention since perturbations in other developmental processes, particularly proliferation, differentiation, and migration, may be antecedents to apoptosis. ${ }^{37}$ Ethanol has long been recognized as a developmental neurotoxicant and induction of apoptosis is now thought to be one facet of the adverse effects of prenatal ethanol exposure. ${ }^{38,39}$ Rat cerebellar cultures undergo apoptosis following exposure to ethanol, possibly due to inhibition of the neurotrophic effects of NMDA. ${ }^{40}$ Exposure of cultured cerebellar granule cells to $28 \mathrm{mM}$ ethanol (a physiological concentration) inhibited differentiation, migration on a laminin substratum, and 
resulted in death by apoptosis. ${ }^{37}$ Methylmercury has been shown in vitro to induce apoptosis in fetal rat telencephalon, ${ }^{41}$ developing murine cerebellar granule neurons, ${ }^{42}$ and rat cerebellar slice cultures. ${ }^{43}$ In cerebellar slices, mercury produced a dose-dependent inhibition of migration of external granule cells and was accompanied by apoptosis of the non-migrating cells. ${ }^{43}$ Mid-gestational exposure to chlorpyrifos, a cholinesterase-inhibiting pesticide, produced changes in proliferation, migration, and apoptosis in rat neuroepithelium. ${ }^{44}$

Apoptosis is believed to underlie the pathogenesis of a number of human neurodegenerative diseases, including Alzheimer's disease (reviewed in ${ }^{45,46}$ ), Huntington's disease, ${ }^{47}$ Parkinson's disease, ${ }^{48}$ and Down's syndrome. ${ }^{49}$ In normal human development, cortical cell number is estimated to peak at 28 weeks of gestation, followed by a reduction in number by about $70 \%$ during the last quarter of prenatal development. $^{50}$ In humans the apoptotic index (TUNELlabeled cells/total cells counted) was relatively high at PND1 and 3 , with subsequent latent smaller peaks at PND30 and PND90, and was zero by PND120. ${ }^{51}$ One disease, Down's syndrome, displays decreased brain cell number due to increased apoptosis and development of dementia in early adulthood. ${ }^{49}$ Other studies are underway to establish an understanding of the role of apoptosis in normal aging of the human nervous system, as regional cell loss during aging is highly region-specific. ${ }^{52}$ For example, cell loss during senescence in the hippocampus has been attributed, in part, to long-term exposure to glucocorticoids, ${ }^{53}$ whereas in mouse olfactory epithelium cell death and proliferation decline with aging in a concomitant fashion. ${ }^{54}$ In nigral dopaminergic neurons, apoptotic cell death is thought to occur as a consequence of normal aging. ${ }^{55}$

Elucidation of how environmental factors affect this process of developmental programmed cell death could further our understanding of a possible cause/effect relationship between early exposure to environmental agents and the purported genetic predisposition identified in some subpopulations to onset and severity of symptoms of numerous neurodegenerative diseases of the human nervous system. Future studies should focus on the functional significance of the pattern formation that is occurring developmentally, the factors modulating this elimination of cells through apoptosis, and how environmental insults may perturb these regional profiles of apoptosis causing aberrant cell number and possibly compromised neurological function.

\section{Materials and Methods}

\section{Animals}

Time-pregnant primiparous Long-Evans rats arrived from Charles River (Portage, ME, USA) on gestational day (GD) 4 (sperm positive on GD0). Animals were housed in an AAALAC-approved animal facility and all experiments were approved in advance by the National Health Effects and Environmental Research Laboratory animal care committee of the USA Environmental Protection Agency. All efforts were made to minimize both the suffering and number of animals used. Pregnant dams were housed individually until they gave birth in standard hanging cages with kiln dried soft wood chips as bedding. Animal rooms were maintained on a $12: 12 \mathrm{~h}$ photoperiod, L:D (0600: 1800), and food (Purina Lab Chow) and water were provided ad libitum. The date that birth was first discovered was assigned as postnatal day 0 (PND0), and the time of birth (a.m. or p.m.) was recorded. Shipment of litters was spaced 1 week apart to generate offspring for PND1, 7, 14 and 21 time points. Adult and aged rats were obtained from the same source as above litters.

\section{Tissue preparation}

Long-Evans rats from different litters $(n=5-9)$ were sacrificed on the same day at postnatal ages 1, 7, 10, 14, 21, 80-90 days, 1 year, and 2 years. Rats were quickly decapitated and whole brains were removed. For ELISA and agarose gel electrophoresis, whole brains from five to nine animals representative from different litters were removed and free-hand dissected into the following regions: brainstem (consisting of medulla oblongata and pons), neocortex (including all of the cortical mantle except the olfactory tubercle and piriform cortex), hippocampus (both dorsal and ventral aspects of the hippocampal formation), and cerebellum (including flocculonodular lobes). Each region was then frozen in isopentane for $30 \mathrm{~s}$ on dry ice, weighed, and stored at $-70^{\circ} \mathrm{C}$ for up to 3 weeks before being assayed. For TUNEL histochemistry, brains from at least three animals from different litters at each age, were cut in half sagittally, quick frozen on dry ice, and stored at $-70^{\circ} \mathrm{C}$ until sectioning on a cryostat.

\section{Cell death ELISA}

Oligonucleosomal DNA was quantified using the Cell Death Detection ELISA $^{\text {PLUS }}{ }^{8}$ (Boehringer Mannheim; Germany) with two modifications. The kit was adapted for use with tissue by using the provided lysis buffer to create cytoplasmic lysates of fresh or frozen brain tissue. To discern the effects of freezing the tissue on values obtained in this assay, a comparison of fresh and frozen tissue was done. On PND1 and PND7, tissues (both fresh and frozen from neocortex, hippocampus, and cerebellum) were assayed at the same time on the same ELISA plate. Freezing the tissue prior to ELISA determination of fragmented cytosolic oligonucleosomes increased the baseline at least $15 \%$ above levels observed in fresh tissue. Due to the logistics of the time-course and regional analyses, all tissues were frozen first and assayed concurrently.

Each pre-weighed, frozen brain region was combined with 10 volumes of lysis buffer and gently homogenized with 15 strokes of a plastic pestle in its respective eppendorf tube. Pooling of two cerebella or four hippocampi from litter-mates was necessary at PND1. One neocortical hemisphere was used for PND7 and all older age groups. The cerebellum and brainstem of adults were cut mid-sagittally and half of the brain was used for TUNEL histochemistry and the other half dissected for ELISA. All tissues were lysed at room temperature for $30 \mathrm{~min}$. Lysate-containing tubes were then centrifuged at 1500 r.p.m. for $10 \mathrm{~min}$ and the supernatant, containing the cytosolic fraction was transferred to a fresh tube. The discarded pellet contained cell nuclei, including the unfragmented high molecular weight DNA, and organelles (including mitochondria), and other cell debris. The retained cytoplasmic fraction contained the mono- and oligonucleosomal fragmented DNA that had leaked into the cytoplasm in the early stages of apoptosis, before plasma membrane breakdown. Twenty $\mu$ l of the cytoplasmic lysate was loaded into a streptavidin-coated plate and combined with immunoreagent mix containing biotinylated antihistone and anti-DNA peroxidase in a 1-step sandwich ELISA (i.e., the $20 \mu \mathrm{l}$ of cytoplasmic sample containing fragmented DNA/histone complexes, the biotinylated anti-histone capture antibody, and the 
peroxidase-conjugated detection antibody were allowed to bind in one step). The plate was incubated for $2 \mathrm{~h}$ on an orbital shaker at 400 r.p.m., then unbound antibodies were removed with three washes. Bound peroxidase was reacted with 2,2'-Azino-di[3-ethylbenzthiazolin-sulfonat(6)] (ABTS) to create a green reaction product that was measured on a Thermo $0_{\max }$ microplate reader (Molecular Devices; Sunnyvale, CA, USA) at $405 \mu \mathrm{m}$ using a reference wavelength of $490 \eta \mathrm{m}$. A standard curve was generated using serial dilutions of the histone-DNA complex which was the positive control provided with the kit to allow linear quantification of fragmented DNA. The histone-DNA complex was assayed in a cytofluorometric DNA assay using Hoechst Dye (Sigma; B2882) and read at $356 \lambda$ (excitation) and $458 \lambda$ (emission). For a given region, all samples at all ages were assayed in the same experiment giving an overall coefficient of variation (CV\%) for sample replicates of $4.87 \%$. Some samples were frozen and assayed on another day to test for stability of ELISA signal. These replicates done on different days had a $7.65 \mathrm{CV} \%$. Detection limits of the assay were $0.5 \mathrm{ng}$ fragmented DNA/mg tissue.

\section{Statistical analysis}

ELISA data are expressed as mean \pm S.E. The experimental design was a split-plot design with the main plots being individual rats and subplots being individual brain regions. The main effects, age (eight levels) and brain region (four levels) were evaluated in an overall ANOVA. Step-down ANOVAs were performed on each region following observation of a significant overall age by region interaction. To ascertain which ages were different from one another within specific brain regions, post hoc Tukey's multiple comparisons were performed with significant effects determined at $P \leqslant 0.05$.

\section{Agarose gel electrophoresis}

Cytoplasmic extracts ( $500 \mu \mathrm{l}$ isolated as described above) were digested with $50 \mu \mathrm{g} / \mathrm{ml}$ DNase-free RNase (Boehringer Mannheim; \#1119 915) for $1 \mathrm{~h}$ at $37^{\circ} \mathrm{C}$, followed by digestion with $100 \mu \mathrm{g} / \mathrm{ml}$ Proteinase $\mathrm{K}$ (Boehringer Mannheim) for $3 \mathrm{~h}$ at $37^{\circ} \mathrm{C}$. Protein was removed by adding an equal volume of Tris-saturated phenol/ chloroform/isoamyl alcohol (25:24:1), vortexing $10 \mathrm{~s}$, and centrifuging at 13000 r.p.m. for $5 \mathrm{~min}$. The aqueous fraction was transferred to a fresh tube and extracted twice with chloroform/isoamyl alcohol (24:1). DNA was precipitated from the aqueous fraction with $1 / 10$ volume of $3 \mathrm{M}$ sodium acetate and 2 volumes of ice cold ethanol at $-20^{\circ} \mathrm{C}$ overnight. Tubes were centrifuged at 13000 r.p.m. at $4^{\circ} \mathrm{C}$ for $30 \mathrm{~min}$, the supernatant was removed, the remaining pellet was washed once with cold $95 \%$ ethanol, and allowed to air dry. The pellet was resuspended in $20 \mu \mathrm{l}$ Tris-EDTA (TE) buffer and incubated $1 \mathrm{~h}$ at $37^{\circ} \mathrm{C}$ with $50 \mu \mathrm{g} / \mathrm{ml}$ RNaseA. Five $\mu$ l of DNA (which correspond to the amount of DNA isolated from $12.5 \mathrm{mg}$ of brain tissue) was combined with $13 \mu \mathrm{l}$ of TE and $2 \mu \mathrm{l}$ of $10 \times$ loading dye $(0.025 \%$ bromophenyl blue in $40 \%$ sucrose) and loaded onto a $0.8 \%$ agarose gel. The agarose gel was run on a gel box (Buffer Puffer ${ }^{\mathrm{TM}}$; Owl Scientific, Woburn, MA, USA) at $30 \mathrm{~V}$ for $10 \mathrm{~min}$ followed by $70 \mathrm{~V}$ for $2 \mathrm{~h}$. A Hindlll digested ADNA marker (Boehringer Mannheim; \#236 250) was run on each gel. Two to three gels for each region were stained with SYBRGold ${ }^{\circledR}$ nucleic acid gel stain (Molecular Probes; S-11494) for 30 min with gentle agitation and scanned on a Fluor $S$ Multilmager (Bio-Rad; Hercules, CA, USA) using 520LP filter at UV320 with a $5 \mathrm{~s}$ integration time. A second set of agarose gels were run from total DNA isolated from PND1 and PND10 cortex and cerebellum to verify results obtained from cytoplasmic DNA gels. Regions were removed, frozen and subsequently lysed in digestion buffer (100 mM NaCl; $10 \mathrm{mM}$ Tris $\mathrm{HCl}, \mathrm{pH}$ 8; $25 \mathrm{mM}$ EDTA, pH 8; 0.5\% SDS; $0.2 \mathrm{mg} / \mathrm{ml}$ Proteinase K) for $12 \mathrm{~h}$ at $50^{\circ} \mathrm{C}$. DNA was extracted and precipitated as described above and then quantified spectrophotometrically. Forty $\mu \mathrm{g}$ of total DNA was incubated $1 \mathrm{~h}$ at $37^{\circ} \mathrm{C}$ with $50 \mu \mathrm{g} / \mathrm{ml} \mathrm{RNaseA}$, loaded onto a $2 \%$ agarose gel after addition of $2 \mu \mathrm{l}$ of $10 \times$ loading dye $(0.025 \%$ bromophenyl blue in $40 \%$ sucrose), and electrophoresed as described above.

\section{TUNEL staining}

Half brains were cut sagittally on a cryostat $\left(12 \mu \mathrm{m}\right.$ at $\left.-16^{\circ} \mathrm{C}\right)$ and mounted on gelatin-coated slides. Representative sagittal sections from each age were stained in parallel for fragmented DNA using the Apoptag ${ }^{\mathbb{R}}$ Plus In Situ Apoptosis Detection kit (Intergen, Gaithersburg, MD, USA). Slide-mounted sections were fixed in 10\% neutral buffered formalin in $0.1 \mathrm{M}$ phosphate buffer $(10 \mathrm{~min}$ ) and postfixed in ethanol/acetic acid ( $2: 1)(5 \mathrm{~min})$ prior to the terminal deoxynucleotidyl transferase catalyzed addition of digoxigenin to the $3^{\prime} \mathrm{OH}$ ends of fragmented DNA. Anti-digoxigenin-peroxidase was then bound to the digoxigenin-labeled DNA, followed by visualization using $3,3^{\prime}$ diaminobenzidine hydrochloride (DAB) as chromogen. Sections were then counterstained with $0.5 \%$ methyl green, dehydrated and mounted under coverslips using DPX. Positive controls provided in the kit were simultaneously processed. To control for non-specific staining, sagittal sections from each age were concurrently stained using the same protocol, but without terminal transferase. No background staining was evident except for some weak background staining throughout cerebellum, which was easily discernable from apoptotic profiles. Stereolnvestigator software (Microbrightfield, Colchester, VT, USA) was used to create camera lucida-type drawings of sagittal sections of brains at each age. Stained cells were labeled with markers in drawings of each region to show distribution.

\section{Acknowledgements}

The authors are grateful for the technical assistance of Braxton Summers and the statistical analyses by Dennis House. The authors are also grateful for the photographic assistance of Keith Tarpely and John Havel, and for the editorial comments of Drs. WR Mundy, and R Zucker on an earlier draft of this manuscript. This manuscript was reviewed by the NHEERL, US Environmental Protection Agency, and approved for publication. Mention of trade names or commercial products does not constitute endorsement or recommendation for use.

\section{References}

1. Chen SC, Curran T and Morgan JI (1995) Apoptosis in the nervous system: new revelations. J Clin. Pathol. 48: 7-12

2. Kuan CY, Roth KA, Flavell RA and Rakic $P(2000)$ Mechanisms of programmed cell death in the developing brain. Trends Neurosci. 23: 291-297

3. Deckwerth TL and Johnson EMJ (1993) Temporal analysis of events associated with programmed cell death (apoptosis) of sympathetic neurons deprived of nerve growth factor. J. Cell Biol. 123: 1207-1222

4. Borovitskaya AE, Evtushenko VI and Sabol SL (1996) Gamma-radiationinduced cell death in the fetal rat brain possesses molecular characteristics of apoptosis and is associated with specific messenger RNA elevations. Mol. Brain Res. 35: 19-30

5. Simonian NA, Getz RL, Leveque JC, Konradi C and Coyle JT (1996) Kainate induces apoptosis in neurons. Neuroscience. 74: 675-683

6. Takei N and Endo Y (1994) Ca2+ ionophore-induced apoptosis on cultured embryonic rat cortical neurons. Brain Res. 652: 65-70

7. Raff MC, Barres BA, Burne JF, Coles HS, Ishizaki Y and Jacobson MD (1993) Programmed cell death and the control of cell survival: lessons from the nervous system. Science. $262: 695-700$ 
8. Bursch W, Kleine L and Tenniswood M (1990) The biochemistry of cell death by apoptosis. Biochem. Cell Biol. 68: 1071-1074

9. Blaschke AJ, Staley Kand Chun J (1996) Widespread programmed cell death in proliferative and postmitotic regions of the fetal cerebral cortex. Development. 122: $1165-1174$

10. Blaschke AJ, Weiner JA and Chun J (1998) Programmed cell death is a universal feature of embryonic and postnatal neuroproliferative regions throughout the central nervous system. J. Comp. Neurol. 396: 39-50

11. Ramachandra S and Studzinski GP (1995) Morphological and biochemical criteria of apoptosis. In Cell Growth and Apoptosis: A Practical Approach, Studzinski GP, ed. New York: IRL Press at Oxford University Press. pp. 119-142

12. Walker PR, Kokileva L, LeBlanc J and Sikorska M (1993) Detection of the initia stages of DNA fragmentation in apoptosis. Biotechniques. 15: 1032-1040

13. Walker PR and Sikorska M (1997) New aspects of the mechanism of DNA fragmentation in apoptosis. Biochem. Cell Biol. 75: 287-299

14. Charriaut-Marlangue $C$ and Ben-Ari $Y$ (1995) A cautionary note on the use of the TUNEL stain to determine apoptosis. Neuroreport. 7: 61-64

15. van Lookeren C, Lucassen PJ, Vermeulen JP and Balazs R (1995) NMDA and kainate induce internucleosomal DNA cleavage associated with both apoptotic and necrotic cell death in the neonatal rat brain. Eur. J. Neurosci. 7: 1627-1640

16. Bayer SA, Altman J, Russo RJ and Zhang X (1993) Timetables of neurogenesis in the human brain based on experimentally determined patterns in the rat. Neurotoxicology. 14: 83-144

17. Spreafico R, Frassoni C, Arcelli P, Selvaggio M and De Biasi S (1995) In situ labeling of apoptotic cell death in the cerebral cortex and thalamus of rats during development. J. Comp. Neurol. 363: 281-295

18. Thomaidou D, Mione MC, Cavanagh JF and Parnavelas JG (1997) Apoptosis and its relation to the cell cycle in the developing cerebral cortex. J. Neurosci. 17: 1075-1085

19. Mesner PW, Epting CL, Hegarty JL and Green SH (1995) A timetable of events during programmed cell death induced by trophic factor withdrawal from neuronal PC12 cells. J. Neurosci. 15: 7357-7366

20. Chan WY and Yew DT (1998) Apoptosis and Bcl-2 oncoprotein expression in the human fetal central nervous system. Anat. Rec. 252: 165-175

21. Zamenhof $S$ and Guthrie D (1995) Programmed cell death enhances uniformity in rat cerebral hemispheres. Dev. Neurosci. 17: 264-266

22. Gould E and McEwen BS (1993) Neuronal birth and death. Curr. Opin. Neurobiol. 3: $676-682$

23. Siman R, Bozyczki-Coyne D and Bhat R (1998) Apoptosis in post-natal rat brain detected in situ with an antibody probe for caspase-mediated proteolysis. Soc. Neurosci. 24: 2

24. Tanaka $M$ and Marunouchi $T$ (1998) Immunohistochemical analysis of developmental stage of external granular layer neurons which undergo apoptosis in postnatal rat cerebellum. Neurosci. Lett. 242: 85-88

25. Tanaka M, Sawada M, Miura M and Marunouchi T (1998) Insulin-like growth factor-I analogue prevents apoptosis mediated through an interleukin-1 beta converting enzyme (caspase-1)-like protease of cerebellar external granular layer neurons: developmental stage-specific mechanisms of neuronal cel death. Neuroscience. 84: 89-100

26. Krueger BK, Burne JF and Raff MC (1995) Evidence for large-scale astrocyte death in the developing cerebellum. J. Neurosci. 15: 3366-3374

27. Taglialatela G, Gegg M, Perez-Polo JR, Williams LR and Rose GM (1996) Evidence for DNA fragmentation in the CNS of aged Fischer-344 rats. Neuroreport. 7: 977-980

28. Maciejewska B, Lipowska M, Kowianski P, Domaradzka-Pytel B and Morys (1998) Postnatal development of the rat striatum - a study using in situ DNA end labeling technique. Acta Neurobiol. Exp. (Warsz). 58: 23-28

29. Holman SD, Collado P, Skepper JN and Rice A (1996) Postnatal development of a sexually dimorphic, hypothalamic nucleus in gerbils: a stereological study of neuronal number and apoptosis. J. Comp Neurol. 376: 315-325

30. Gorman AM, Orrenius S and Ceccatelli S (1998) Apoptosis in neuronal cells: role of caspases. Neuroreport. 9: R49-R55

31. Adams JM and Cory S (1998) The Bcl-2 protein family: arbiters of cell survival. Science. 281: 1322-1326

32. Cryns VL and Yuan J (1998) The cutting edge: Caspases in apoptosis and disease. In When Cells Die: A Comprehensive Evaluation of Apoptosis and Programmed Cell Death, Lockshin RA, Zakeri Zf and Tilly JL, eds. New York: Wiley-Liss. pp. 177-210
33. Urase K, Fujita E, Miho Y, Kouroku Y, Mukasa T, Yagi Y, Momoi MY and Momoi T (1998) Detection of activated caspase-3 (CPP32) in the vertebrate nervous system during development by a cleavage site-directed antiserum. Dev. Brain Res. 111: $77-87$

34. Wood KA and Youle RJ (1995) The role of free radicals and p53 in neuron apoptosis in vivo. J. Neurosci. 15: 5851-5857

35. Frankowski H, Missotten M, Fernandez PA, Martinou I, Michel P, Sadoul R and Martinou JC (1995) Function and expression of the Bcl-x gene in the developing and adult nervous system. Neuroreport. 6: 1917-1921

36. Roberts RA, Nebert DW, Hickman JA, Richburg JH and Goldsworthy TL (1997) Perturbation of the mitosis/apoptosis balance: a fundamental mechanism in toxicology. Fundam. Appl. Toxicol. 38: 107-115

37. Liesi $P$ (1997) Ethanol-exposed central neurons fail to migrate and undergo apoptosis. J Neurosci. Res. 48: 439-448

38. Miller MW (1995) Effect of pre- or postnatal exposure to ethanol on the total number of neurons in the principal sensory nucleus of the trigeminal nerve: cell proliferation and neuronal death. Alcohol Clin. Exp. Res. 19: 1359-1363

39. Hoffman PL and Tabakoff B (1996) To be or not to be: how ethanol can affect neuronal death during development. Alcohol Clin. Exp. Res. 20: 193-195

40. Castoldi AF, Barni S, Randine G, Costa LG and Manzo L (1998) Ethanol selectively interferes with the trophic action of NMDA and carbachol on cultured cerebellar granule neurons undergoing apoptosis. Dev. Brain Res. 111: 279289

41. Monnet-Tschudi $F$ (1998) Induction of apoptosis by mercury compounds depends on maturation and is not associated with microglial activation. J. Neurosci. Res. 53: 361-367

42. Bulleit RF and Cui $H$ (1998) Methylmercury antagonizes the survival-promoting activity of insulin- like growth factor on developing cerebellar granule neurons. Toxicol. Appl. Pharmacol. 153: 161-168

43. Kunimoto M and Suzuki T (1997) Migration of granule neurons in cerebellar organotypic cultures is impaired by methylmercury. Neurosci. Lett. 226: 183186

44. Roy TS, Andrews JE, Seidler FJ and Slotkin TA (1998)Chlorpyrifos elicits mitotic abnormalities and apoptosis in neuroepithelium of cultured rat embryos. Teratology. 58: 62-68

45. Barinaga M (1998) Is apoptosis key in Alzheimer's disease? [news]. Science. 281: $1303-1304$

46. Dragunow M, MacGibbon GA, Lawlor P, Butterworth N, Connor B, Henderson C, Walton M, Woodgate A, Hughes P and Faull RL (1997) Apoptosis, neurotrophic factors and neurodegeneration. Rev. Neurosci. 8: 223-265

47. Butterworth NJ, Williams L, Bullock JY, Love DR, Faull RL and Dragunow M (1998) Trinucleotide (CAG) repeat length is positively correlated with the degree of DNA fragmentation in Huntington's disease striatum. Neuroscience. 87: 4953

48. Burke RE and Kholodilov NG (1998) Programmed cell death: does it play a role in Parkinson's disease? Ann. Neurol. 44: S126-S133

49. Busciglio J and Yankner BA (1995) Apoptosis and increased generation of reactive oxygen species in Down's syndrome neurons in vitro. Nature. 378: 776 779

50. Rabinowicz T, de Courten-Myers GM, Petetot JM, Xi G and de los R (1996) Human cortex development: estimates of neuronal numbers indicate major loss late during gestation. J. Neuropathol. Exp. Neurol. 55: 320-328

51. Lossi L, Zagzag D, Greco MA and Merighi A (1998) Apoptosis of undifferentiated progenitors and granule cell precursors in the postnatal human cerebellar cortex correlates with expression of BCL-2, ICE, and CPP32 proteins. J. Comp. Neurol. 399: $359-372$

52. Coleman PD and Flood DG (1987) Neuron numbers and dendritic extent in normal aging and Alzheimer's disease. Neurobiol. Aging 8: 521-545

53. Reagan LP and McEwen BS (1997) Controversies surrounding glucocorticoidmediated cell death in the hippocampus. J. Chem. Neuroanat. 13: 149-167

54. Fung KM, Peringa J, Venkatachalam S, Lee VM and Trojanowski JQ (1997) Coordinate reduction in cell proliferation and cell death in mouse olfactory epithelium from birth to maturity. Brain Res. 761: 347-351

55. Anglade P, Vyas S, Hirsch EC and Agid Y (1997) Apoptosis in dopaminergic neurons of the human substantia nigra during normal aging. Histol. Histopathol. 12: $603-610$ 